\title{
Rectovaginal Fistula: A Common Diagnostic Error With Significant Consequences in Girls With Anorectal Malformations
}

\author{
By Nelson G. Rosen, Andrew R. Hong, Samuel Z. Soffer, George Rodriguez, and Alberto Peña \\ New Hyde Park, New York
}

\begin{abstract}
Background/Purpose: Rectovaginal fistula is a term that continues to be used frequently to describe girls with anorectal malformations. This study attempts to evaluate the true frequency of this anomaly and the consequences of its misdiagnosis.
\end{abstract}

Methods: A retrospective review of all girls with anorectal malformations treated by the senior author from 1980 through September 2000 was performed, and the pertinent literature was reviewed.

Results: Of the 617 patients identified, only 6 were found to have a true rectovaginal fistula, an incidence of $1 \%$. A total of 139 of the 617 patients were referred after a previous repair. Of these, 42 had a diagnosis of recto-vaginal fistula originally. The diagnosis was incorrect in all 42 . Twelve patients had a rectovestibular fistula, and 30 had a cloaca. The 30 cloaca patients, because of the misconception that they had a rectovaginal fistula, underwent an initial repair of only the rectal component of the malformation, leaving all patients with a urogenital sinus necessitating a second complete repair.

Conclusions: The use of the term rectovaginal fistula is common, despite a true incidence of $1 \%$ in girls with anorectal malformations. The majority of girls will have either a rectovestibular fistula or a cloaca. Such diagnostic errors may lead to the use of inappropriate surgical techniques, incomplete repair, and unnecessary morbidity.

J Pediatr Surg 37:961-965. Copyright 2002, Elsevier Science (USA). All rights reserved.

INDEX WORDS: Rectovaginal fistula, rectovestibular fistula cloaca, urogenital sinus.
$\mathbf{T}$ HE BELIEF that rectovaginal fistula is a common female anorectal malformation continues to be relatively widespread, as evidenced by the prominent role the diagnosis plays in many reviews of anorectal malformations. ${ }^{1-12}$ Based on the paucity of this type of malformation seen in the senior author's large series, we suspect that the true incidence of this malformation is substantially lower. We also suspect that the misdiagnosis of other more common malformations as rectovaginal fistulas might result in the use of inappropriate procedures for reconstruction of these malformations. This prompted a retrospective review of our experience with the treatment of 617 girls with anorectal malformations with the intent of determining the true incidence of rectovaginal fistula.

\section{MATERIALS AND METHODS}

The medical records of 617 girls with anorectal malformations treated by the senior author from 1980 through September 2000 were reviewed retrospectively. Both patients who underwent their primary repair at our institution $(\mathrm{n}=478)$, and those referred to us after a repair had been performed at another institution $(n=139)$ were evaluated. Criteria evaluated included original diagnosis, physical state on presentation, operative findings, and functional result.

All patients referred with a prior diagnosis of rectovaginal fistula who had undergone a repair at another institution $(\mathrm{n}=42)$ were reclassified according to the anatomic findings seen after examination or reoperation. Functional outcome data were assessed for these patients when available $(n=33)$. These results were compared against historical controls with the same diagnoses from a series published by the senior author. ${ }^{13}$
The English-language literature of the past 71 years was reviewed for significant series of patients with anorectal malformations. Data were compiled to determine the incidence of the various female anorectal malformations at different points in time up to and including the current series.

\section{RESULTS}

Among 617 girls with anorectal malformations who were treated, 6 were identified as having a true rectovaginal fistula for an incidence of $1 \%$. Figure 1 shows the features of a rectovaginal fistula. Among these 617 patients, 478 were referred for primary repair, and 139 were referred for reoperation after a prior repair. The incidence of the varying malformations encountered among these 2 groups are summarized in Table 1.

Forty-two of the 139 patients referred after a definitive repair carried the diagnosis of rectovaginal fistula. Physical examination and intraoperative findings showed that actually none of these patients had evidence of a prior

From the Division of Pediatric Surgery, Schneider Children's Hospital, New Hyde Park, NY.

Presented at the 53rd Annual Meeting of the Section on Surgery of the American Academy of Pediatrics, San Francisco, California, October 19-21, 2001.

Address reprint requests to Alberto Peña, MD, Division of Pediatric Surgery, CH-158, Schneider Children's Hospital, 269-01 76th Ave, New Hyde Park, NY 11040.

Copyright 2002, Elsevier Science (USA). All rights reserved. 0022-3468/02/3707-0003\$35.00/0

doi:10.1053/jpsu.2002.33816 


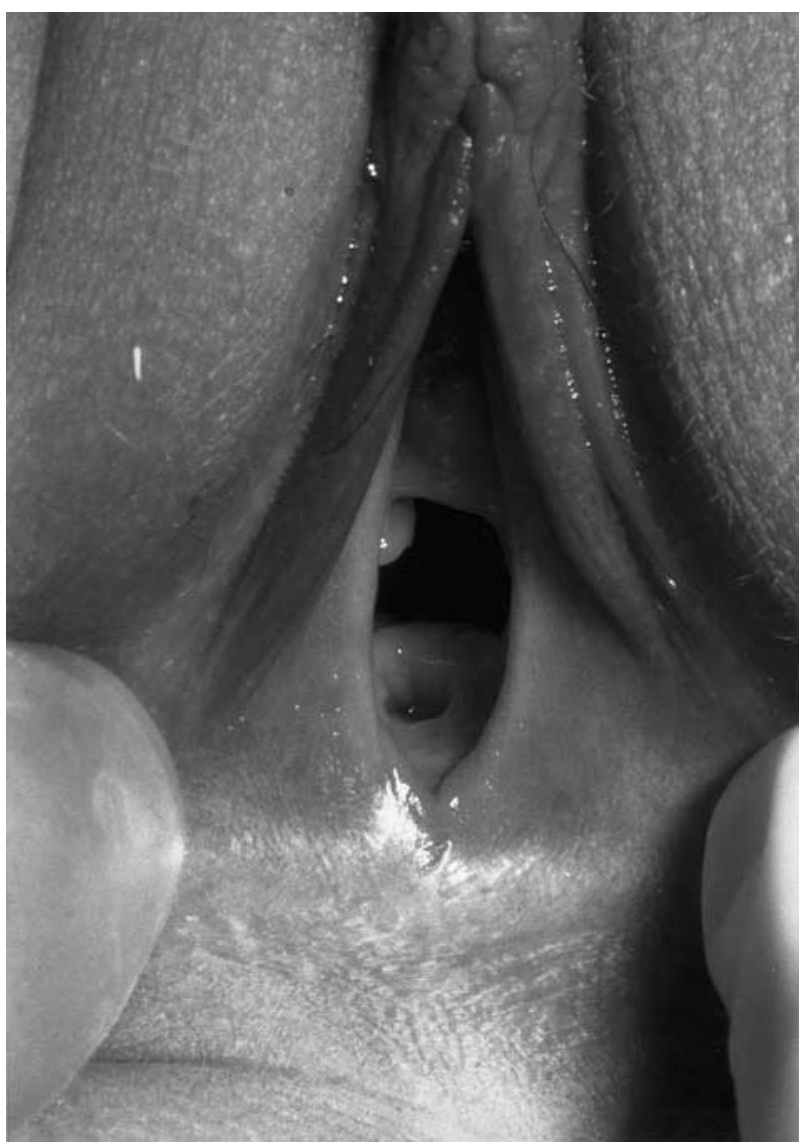

Fig 1. A true rectovaginal fistula. The rectal orifice is seen internal to the hymenal ring.

rectovaginal fistula. Thirty of those patients had a persistent urogenital sinus. This was considered evidence that the original malformation was a cloaca. Twelve patients had a blind pouch opening in the posterior vestibule as may be seen in Fig 2. This was considered evidence of the previous presence of a rectovestibular fistula.

All 30 cloaca patients with a persistent urogenital sinus underwent reoperation to repair the urogenital sinus. Urinary control data were available for 25 patients. Among these patients 19 of $25(76 \%)$ are continent, 3 of $25(12 \%)$ remain dry with intermittent catheterization, and 3 of $25(12 \%)$ required a continent diversion. Fecal control data were available for 20 of these patients with 5 of $20(25 \%)$ being totally continent, 6 of $20(30 \%)$

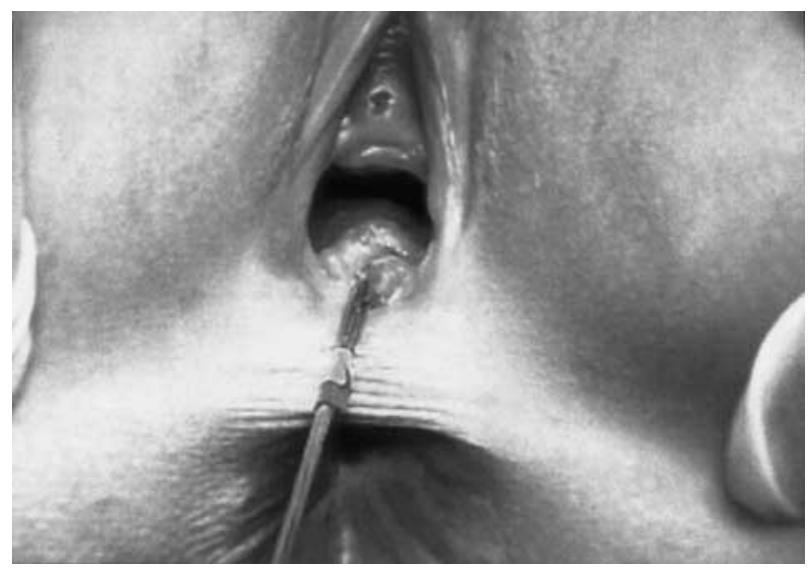

Fig 2. Residual evidence of a rectovestibular fistula in a patient who was considered to have a rectovaginal fistula. The instrument shows the residual pouch the remains in the posterior vestibule.

having voluntary bowel movements with some soiling, and 9 of $20(45 \%)$ totally incontinent. Eleven $(55 \%)$ of the patients had voluntary bowel movements as opposed to $71 \%$ of patients in a previously published series by the senior author. No statistical analysis was performed because of the limited sample size.

For the 12 rectovestibular fistula patients, follow-up data were available for 8 . Among these patients, 2 (25\%) were fecally incontinent, 2 (25\%) had voluntary bowel movements with some soiling, and $4(50 \%)$ were totally continent. Comparatively, in a previously reported series by the senior author, $93 \%$ of patients with rectovestibular fistula had voluntary bowel movements after repair. No statistical analysis was performed on these data because of the limited sample size.

The results of the English-language literature review are shown in Table 2. The incidence of rectovaginal fistula ranged from $0 \%$ to $84 \%$. On reviewing the data it was observed that the relative incidence of rectovaginal fistula decreased over time, coinciding with an increase in the relative incidence of rectovestibular fistula and cloaca.

\section{DISCUSSION}

The low incidence of rectovaginal fistula in this series contrasts strongly with many published series of the past 70 years. This marked discrepancy can be explained by 2 possibilities. One is that there was a sudden change in the

Table 1. Incidence of the Various Malformations That Occurred in the Current Series

\begin{tabular}{|c|c|c|c|c|c|c|c|}
\hline $\begin{array}{l}\text { Operative } \\
\text { Status }\end{array}$ & $\begin{array}{c}\text { No. of } \\
\text { Patients }\end{array}$ & No Fistula & $\begin{array}{l}\text { Perineal } \\
\text { Fistula }\end{array}$ & $\begin{array}{l}\text { Rectovestibular } \\
\text { Fistula }\end{array}$ & $\begin{array}{l}\text { Rectovaginal } \\
\text { Fistula }\end{array}$ & Cloaca & Other \\
\hline Primary & 478 & 13 & 36 & 135 & 6 & 234 & $54^{*}$ \\
\hline Reoperative & 139 & 3 & 3 & 44 & 0 & 64 & $25 t$ \\
\hline Total & 617 & $16(2.6 \%)$ & $39(6.3 \%)$ & $179(29 \%)$ & $6(1 \%)$ & $298(48 \%)$ & $49(8 \%)$ \\
\hline
\end{tabular}

*Includes 24 cloacal exstrophy, 24 patients with complex malformations hitherto unclassified, 4 rectal atresia, and 2 rectal stenosis patients. tIncluded 6 complex malformation patients and 19 patients with uncertainty of the diagnosis before the first repair. 
Table 2. Literature Review of the Incidence of Rectovestibular Fistula, Rectovaginal Fistula, and Cloaca Including the Current Series

\begin{tabular}{|c|c|c|c|c|}
\hline Study/Year & $\begin{array}{l}\text { No. of } \\
\text { Patients }\end{array}$ & $\begin{array}{l}\text { Rectovestibular } \\
\text { Fistula }\end{array}$ & $\begin{array}{l}\text { Rectovaginal } \\
\text { Fistula }\end{array}$ & Cloaca \\
\hline Wangensteen and Rice, $1930^{1}$ & 25 & $6(24 \%)$ & $9(36 \%)$ & 0 \\
\hline Brenner, $1938^{2}$ & 23 & $10(43 \%)$ & $3(13 \%)$ & 0 \\
\hline Ladd and Gross, $1941^{5}$ & 70 & 0 & $59(84 \%)$ & $1(2 \%)$ \\
\hline Santulli et al, $1952^{4}$ & 31 & 0 & $20(65 \%)$ & 0 \\
\hline Gross, $1953^{5}$ & 193 & 0 & $143(74 \%)$ & 0 \\
\hline Santulli, $1962^{6}$ & 106 & 0 & $64(60 \%)$ & 0 \\
\hline Stephens and Smith, $1963^{7}$ & 40 & $15(38 \%)$ & $4(10 \%)$ & $9(22 \%)$ \\
\hline Swenson and Donellan, 19678 & 19 & 0 & $15(79 \%)$ & 0 \\
\hline Santulli et al, $1971^{9}$ & 481 & $159(33 \%)$ & $118(25 \%)$ & $23(5 \%)$ \\
\hline Bill et al, $1975^{10}$ & 46 & $17(37 \%)$ & 0 & $8(17 \%)$ \\
\hline Japan Study Group, $1982^{11}$ & 98 & $52(53 \%)$ & $4(4 \%)$ & $15(15.3 \%)$ \\
\hline Stephens and Smith, $1988^{12}$ & 92 & $34(37 \%)$ & $8(9 \%)$ & $8(9 \%)$ \\
\hline Stephens and Smith, 1988 summary of 11 author's series ${ }^{12}$ & 951 & $258(27 \%)$ & $183(19 \%)$ & $51(5 \%)$ \\
\hline Current series, 2001 & 617 & $179(29 \%)$ & $6(1 \%)$ & $298(48 \%)$ \\
\hline
\end{tabular}

true incidence of the malformation. We strongly doubt this to be the case. Much more likely is that there is now a much better understanding of the true anatomy of the different malformations and that a cloaca is less commonly mistaken for a rectovaginal fistula.

What continues to be of concern is why these malformations continue to be frequently misdiagnosed despite the fact that the majority can be diagnosed correctly on physical examination alone. An anal orifice visible on the perineum with a normal vagina and urethra is indicative of a perineal fistula. If the opening is in the posterior vestibule, outside of the hymen, the patient has a rectovestibular fistula. If only one orifice is seen between the labia, the child has a cloaca. If physicians caring for infants with these malformations would understand this simple concept, a large number of the misdiagnoses would be avoided.

We admit that it is not always possible to make the diagnosis on physical examination alone. For instance, a small group of patients (3\% in our series) will have imperforate anus with no fistula. This malformation most commonly occurs in association with trisomy 21 . Girls

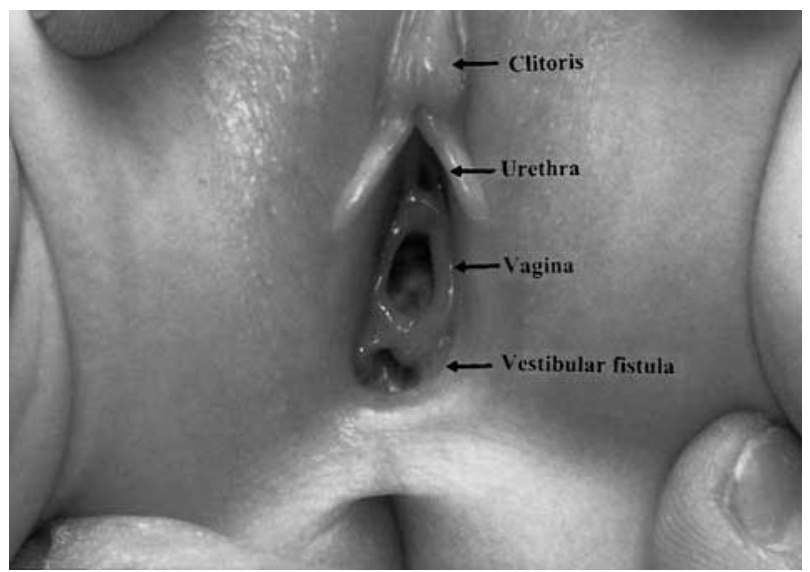

Fig 3. Preoperative appearance of a real rectovestibular fistula. with this malformation have a normal-appearing vagina and urethra, but no visible anal orifice. Interestingly enough, patients with a true rectovaginal fistula will have this same initial appearance. However, closer inspection frequently will show the presence of an orifice in the posterior wall of the vagina, internal to the hymenal ring (Fig 1). If anything is unclear after physical examination, the diagnosis may be confirmed utilizing augmented pressure colostography and endoscopy. ${ }^{14}$ It should be emphasized that these last 2 types of malformations are

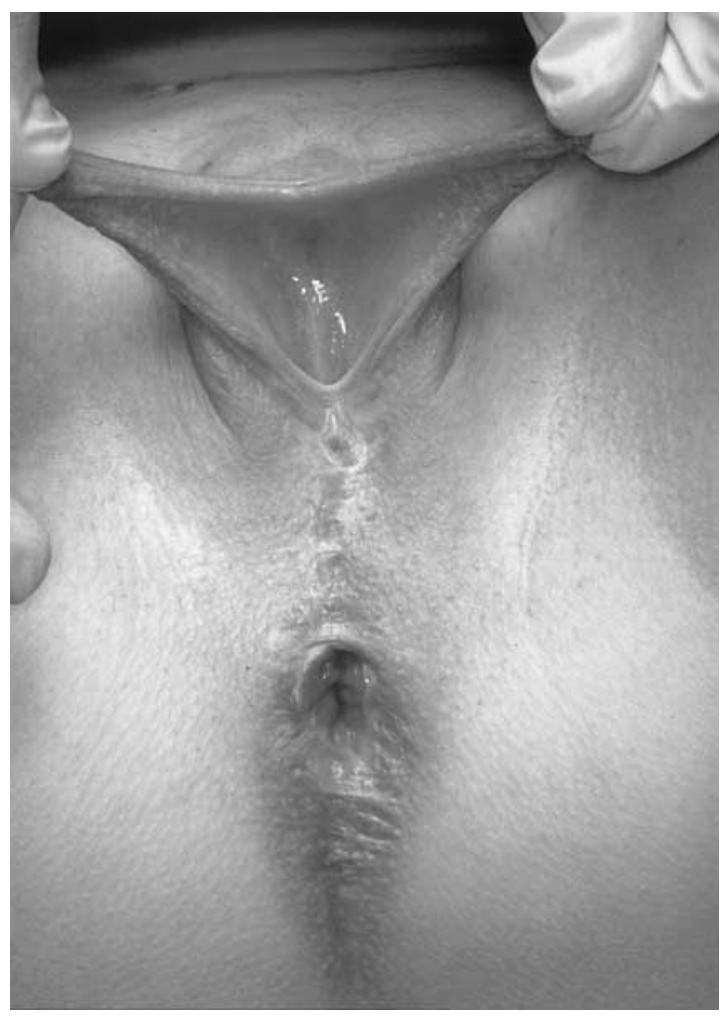

Fig 4. Persistent urogenital sinus after repair of the rectal component of a cloaca that was thought to be rectovaginal fistula. 
rare and make up only a total of $4 \%$ of the patients in our entire series. Consequently, the majority of anorectal malformations in girls can be diagnosed correctly on physical examination alone.

The literature review itself required considerable flexibility in interpretation when viewed in the context of our current understanding of these malformations. Several series relied on classification schemes that did not differentiate between rectovaginal fistula, rectovestibular fistula, and cloaca. For example, in Stephens and Smith's 1971 text, which included a synthesis of 29 published series of anorectal malformations with a total of 3,384 patients, 816 patients were categorized as having a rectovaginal fistula with a notation that this group included rectocloacal and rectofourchette fistulas. ${ }^{15}$ The investigators noted that this "hodepodge" grouping generated much confusion when attempting to analyze the relative incidences of the malformations. ${ }^{15}$

This is not just a matter of semantics. Of the 30 cloaca patients referred to us after their primary repair, all required a second operation to repair the persistent urogenital sinus. It is possible that some surgeons prefer to repair the rectal component of a cloaca at the initial procedure and leave the urogenital sinus for a secondary procedure. We do not agree with this approach. It seems ludicrous to subject these patients to more surgery than is necessary. Failure to treat the urogenital sinus exposes the patient to an increased risk of urinary tract infection, and to postmicturition incontinence caused by urinary hydrocolpos. ${ }^{16}$

We suspect, however, that most of the surgeons that performed these operations did not intentionally leave a urogenital sinus behind. Instead, they were probably under the mistaken impression that they were dealing with a rectovaginal fistula and did not even consider that a repair of the urogenital sinus was necessary. Had they understood that the patient had a cloaca, most likely the proper operation would have been performed at the outset.

Of the rectovestibular fistula patients with available follow-up data $(n=8), 75 \%$ had voluntary bowel move- ments as opposed to $93 \%$ of patients in the author's prior series. Although the sample size of the former group is too limited to allow a statistically significant comparison, these figures do suggest a poorer outcome for these patients. For the 2 incontinent patients in the rectovestibular group, we attribute this to the use of an abdominoperineal approach with an endorectal dissection. Given the fact that a rectovestibular fistula can be repaired posteriorly without entering the abdominal cavity, the use of an abdomino-perineal approach probably is not justified.

Of the cloaca patients with follow-up data for fecal control available $(n=20), 55 \%$ had voluntary bowel movements as opposed to $71 \%$ from the prior series. Although this suggests that the outcome is worse for patients who required a second operation, the limited sample size precludes formal statistical evaluation.

Our series had a higher incidence of cloaca $(n=298$, $48 \%$ ) than any other series mentioned in this review (Table 2). This probably is more reflective of our role as a major referral center for the treatment of complex anorectal malformations than it is of the true incidence of cloaca. We suspect that the true spectrum of female anorectal malformations is better represented by the series published by Bill et al (Table 2). ${ }^{10}$ This review is very thorough in its diagnostic standards, but its discussion of the data focused on the embryology of these malformations rather than the startling implications of the their data with respect to operative treatment. It is the consequences of these implications that necessitated our review.

Accuracy in diagnosis is essential for the correct planning of the total care of patients with anorectal malformations. There is no question that a single definitive operation is better for the patient than multiple procedures. It cannot be overemphasized that a thorough physical examination of the girl with an anorectal malformation with particular attention paid to the genitalia, and an understanding of the anatomic possibilities and their relative incidences will facilitate a correct diagnosis in the majority of cases.

\section{REFERENCES}

1. Wangensteen O, Rice C: Imperforate anus: A method of determining the surgical approach. Ann Surg 92:77-81, 1930

2. Brenner EC: The rectum and anus, in Brenner EC: Pediatric Surgery. Philadelphia, PA, Lea \& Febinger, 1938, pp 537-571

3. Ladd WE, Gross RF: Malformations of the anus and rectum, in Ladd WE, Gross RF: Abdominal Surgery in Infancy and Childhood. Philadelphia, PA, Saunders, 1941, pp 166-187

4. Santulli TV: The treatment of imperforate anus and associated fistulas. Surg Gynecol Obstet 95:601-614, 1952

5. Gross RE: Malformations of the anus and rectum, in Gross RE: The Surgery of Infancy and Childhood. Philadelphia, PA, Saunders, 1953, pp 348-367

6. Santulli TV: Imperforate anus, in Benson CD, Mustard WT,
Ravitch MM, et al (eds): Pediatric Surgery. Chicago, II, Year Book Medical Publishers, 1962, pp 821-836

7. Stephens FD: Congenital malformation of the rectum and anus in female children, in Stephens FD: Congenital malformations of the rectum, anus and genito-urinary tracts. Edinburgh \& London, E. \& S. Livingstone, 1963, pp 42-61

8. Swenson O, Donellan WL: Preservation of the puborectalis sling in imperforate anus repair. Surg Clin North Am 47:173-193, 1967

9. Santulli TV, Schullinger JN, Kieseweitter WB, et al: Imperforate Anus: A Survey From the Members of the Surgical Section of the Americal Academy of Pediatrics. J Pediatr Surg 6:484-487, 1971

10. Bill AH, Hall DG, Johnson RJ: Position of rectal fistula in 
relation to the hymen in 46 girls with imperforate anus. J Pediatr Surg 10:361-365, 1975

11. The Japan Study Group of Anorectal Anomalies: A Group Study for the Classification of Anorectal Anomalies in Japan With Comments to the International Classification (1970). J Pediatr Surg 17:302-308, 1982

12. Stephens FD, Smith ED (eds): Anorectal Malformations in Children: Update 1988. March of Dimes Birth Defects Foundation, Birth Defects: Original article series 24(4). New York, NY, Alan R. Liss Inc., 1988
13. Peña A: Anorectal Malformations. J Pediatr Surg 4:35-47, 1995

14. Gross GW, Wolfson PJ, Pē̄a A: Augmented-pressure colostogram in imperforate anus with fistula. Pediatr Radiol 21:560-562, 1991

15 Stephens FD, Smith ED: Anorectal malformations in children. Chicago, IL, Year Book Medical Publishers, 1971

16. Williams DI, Bloomber S: Urogenital sinus in the female child. J Pediatr Surg 11:51-56, 1976

\section{Discussion}

Dr Bhattacharrya (Newark, NJ): When you look at the urethral opening on the perineum of the girl, sometimes it opens and it usually does right at the perineum, sometimes you can have what is called a female hypospadias where it opens in the anterior wall of the vagina. Many of these patients do not have any symptoms, and no treatment usually is advocated for them. However, the same patient of hypospadias also had a fistula opening into posterior wall of the vagina, that would be a rectovaginal fistula, some might consider this to be a cloaca. How do you distinguish the patient that needs reconstruction of the urethra? Have you done any studies with your dynamics to evaluate bladder neck obstruction, or are you perhaps operating on a lot of patients who do not need a urethroplasty?

N.G. Rosen (response): Currently, I do not believe we are doing anything with urodynamic studies to answer the question of what degree of female hypospadias or how short of a common-channel cloaca requires correction of the urethral component. However, I think that is pretty much predominantly an experiential matter.

As you say, clearly, we consider these if you have a minor degree of female hypospadias in the posterior vaginal wall; we consider that a very short commonchannel cloaca. However, most of those short commonchannel cloacas do not require very much repair of the urethral components so that was not considered an indication in this series for total reoperation for what you would consider a very short urogenital sinus. These were all significant patients that led to urinary hydrocolpos and postmicturition incontinence and increased incidence of urinary tract infections. These were significant urogenital sinuses.

Alberto Peña (response): We separate vestibular and cloacas and perineal in our classification. But I always like to say that mother nature does not respect our classifications.

So what you are referring to is a malformation that looks just "in between." You could call the deep vestibular fistula with a significant female hypospadias which for some people we will call that cloaca of the benign type. Some others will use the term female hypospadias with a deep vestibular fistula.

If you can see only one orifice and you cannot really see the urethra and vagina, by definition that is a cloaca. What we do in those patients is to repair, of course, the rectal component, and we do not have to go through the entire treatment of the urogenital sinus, either total urogenital mobilization or separation of the vagina. When we see that the patient has just a mild female hypospadias, we do not touch that urethra because we know it is clinically irrelevant. We simply do what we call introitusplasty which is to make a vaginal opening, make sure it is wide open, and we know that the patient also will have the urethral opening a little bit deeper than normal. 